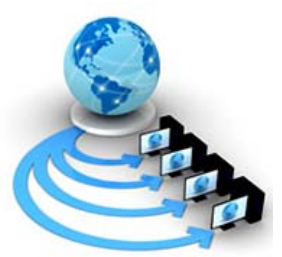

\title{
AN ANALYTICAL REVIEW ON WIRELESS SENSOR CLUSTERING FOR THE PROLONG NETWORK LIFE TIME
}

\author{
Navdeep Kumar Chopra \\ Ph.D (Research Scholar), CSE \\ IKGPTU, Jalandhar, India
}

\author{
Rajesh Kumar Singh \\ Professor \& Principal \\ SUS Institute of Computer, Mohali, India
}

\begin{abstract}
Wireless sensor network is the group of small units called nodes which has gained a lot of light due to its variant applications in various sectors. The tiny mechanical devices referred as sensor nodes are deployed in the very rough area and they are left unattended to uninterruptedly report about the environment parameters .Nodes in rough areas rapidly diminish energy resources, which lead to disruption in network services. This is the main problem of data collection scenarios in which CH's have a huge burden of collecting and relaying statistics. The relay load on heads particularly intensifies as the sink distance decreases. For balancing the load of traffic and the energy consumption in WSN, the CH role must be switched among all the network nodes and the sizes of cluster must be carefully determined at every portion of the network. These devices have energy which is consumed during a long time at processing, gathering, aggregation and transmission of data. So, clustering approach is applied to reduce the consumption of data and give prolonged life to the network. This paper surveyed about the clustering mechanism, its protocols and various issues regarding it. The various parameters of the clustering in WSN are discussed.
\end{abstract}

Keywords: cluster heads (CH); distributed clustering protocol; periodic clustering; time division multiple Access (TDMA)

\section{INTRODUCTION}

In the modern era, the interest in the wireless sensor network has increased enormously. All the application like military, defense and environment monitoring use the sensors to have knowledge about the parameters like pressure, temperature, light, humidity and chemical activity without even bothering about it [1]. The sensors in the nodes even work if left unattended. The researchers gather the information transferred by sensors. In the field of military, while the work of chemical activity and radiation is in growth, the maximum value needs to attentive the workers. For the enhancement of the network fidelity in the measurement, the data aggregation is helpful in energy saving by lessening the communication overhead within the network [2]. With the development in the system of micro electro mechanical, the integration of wireless sensors with wireless communication takes place [3]. It is the gathering of small devices like sensor nodes which are distributed all over the network. Nodes are the tinniest device in the network which is the combination of processing, interaction and sensing capabilities [4]. The main components of the node like battery, processor, transceiver and energy are limited. The wireless sensor nodes are manly of two types: (a) heterogeneous (which has variable sensing, communication and processing capabilities) (b) homogeneous node (fitted with small amount of energy, sensing, communication and processing capabilities'. Wireless sensor network are used in various application of military, surveillance, security, healthcare and disaster management. There are large number of nodes or terminals in the wireless sensor network with restricted processing and energy levels. These all components are collaborated together to work in an ad-hoc network without the need of any infrastructure and central control point. The sensor node takes information (packets) from the moving vehicles (targets) and transfers it to the base station.

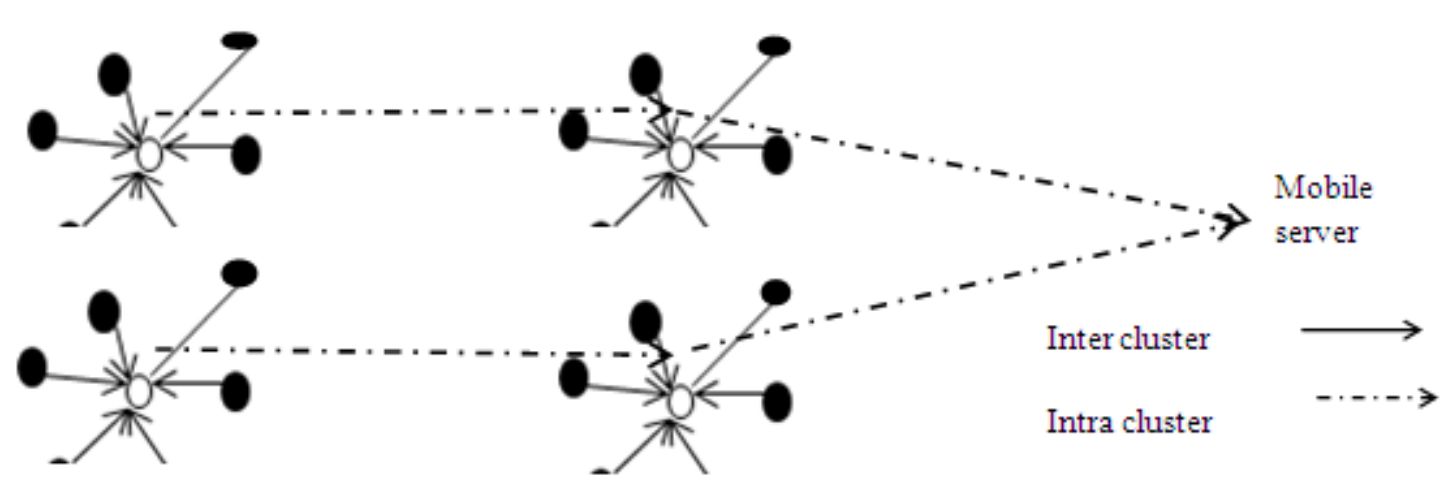

Figure 1. Flow of data in a clustered network

The sensor nodes in the ad-hoc network are energy constrained and can also do data aggregation in order to use energy efficiently [5]. The energy needed to send data is determined based on the distance between the nodes and the amount of bits which are being transmitted. The energy needed for receiving also depends on the amount of bits being received [6].The data aggregation is supported through clustering if efficient work organization in the network has to 
be done. The nodes are partitioned into smaller groups called cluster, every cluster has its own coordinator which is known as cluster head. Considering the cluster head, numbers of member nodes are there in two-tier architecture. The flow of data is depicted in the figure 1 within the clustered network. It is being shown that the cluster heads are at above level in the hierarchy of two-tier while the other nodes are considered as the member nodes at the low level. The member nodes provides the data to the linked $\mathrm{CH}$ (cluster heads) [2]. The $\mathrm{CH}$ accumulates the data and transferred it to the central base by means of other CHs.

As the CHs forward the data over lengthy distances thus there is a huge energy loss. To solve this problem, network re-clustering is required in which the nodes which have abundant energy will serve as the cluster heads.

The concept of re-clustering resulted in the division of energy to all nodes. With the achievement of energy efficiency, the clustering lessens the packet collision and channel contention for improved network with more loads [7]. The major objective of clustering is the improvement of network lifetime and is also considered as the main parameter for evaluating the network performance.

The normal clustering used in the data processing and wired networks cannot be used as the deployment of the network is dynamic and no nodes are aware about the other node location. WSN (Wireless sensor network) is entirely dynamic. The nodes in the network operate with battery power having limited energy. In this type of WSN network distributed clustering protocol is used and it should have low message overhead. The researchers mainly focus on the creating the centralized and distributed overhead to evaluate the connected dominating sets (collection of cluster heads in the network) [8].

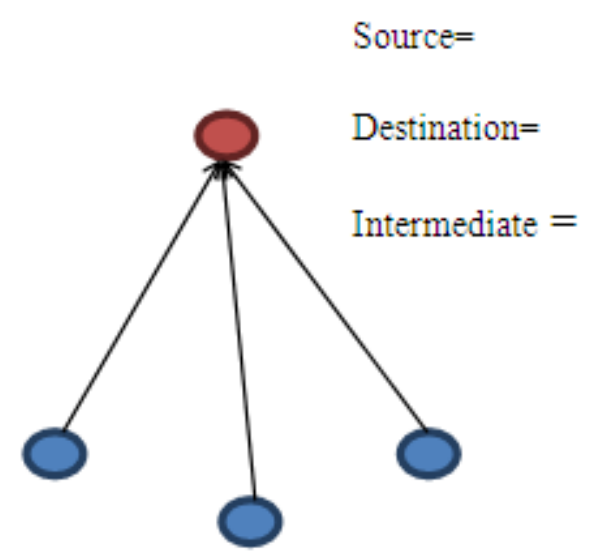

Centralized network

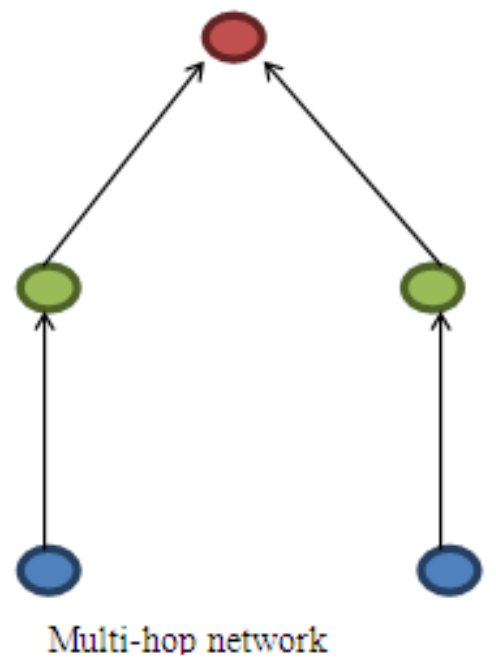

Figure 2. Centralized with multi-hop networks

Sometimes due to harsh environmental circumstances, an unexpected failure in the network occurs. To resolve this, periodic clustering is needed to heal the disconnected regions as the parameters (like remaining energy and node degree) used are dynamic. The sensor nodes in the network have transmitter and receiver which have some energy requirements which are described as follows:

$$
\begin{gathered}
E_{\text {transmiiting }}=\left(E_{\text {elec }}+K\right)+\left(E_{\text {amp }} * K * d^{2}\right) \\
\text { [1] } E_{\text {transmiiting }}=\left(E_{\text {elec }}+K\right)
\end{gathered}
$$

In the above equation 1 and 2 , there are some terms which are defined as follows:

$\mathrm{E}_{\text {elec }}=$ Energy being dissipated for running the transmitter

\section{A. Protocol in wireless sensor network}

In the wireless sensor network, the protocols are adapted to organize the network working and conditions. Based on protocol condition the whole working of the network is organized. Below section defines the routing protocols:

\section{B. LEACH (Low energy Adaptive Clustering \\ Hierarchy)}

This protocol is utilized for data fusion in hierarchical routing. In this main task of communication, data aggregation and data fusion is with cluster head node. The
$E_{a m p}=$ Transmission amplifier energy dissipation

$K \quad=$ Length of the message (bits)

$d \quad=$ Distance between transmitter and the receiver

When there is direct transmission of data between sender and the receiver, so at this time energy required for transmitter amplifier circuit is evaluated by equation 1 [8]. But, in a multi-hop network energy needed for transmitting packets or information from source to terminal node in the multi hope network will be half to that of direct transmission which is described in the equation $3[6,8,9]$.

$$
E_{\text {transmiiting }}=\left(E_{\text {elec }}+K\right)+\left(E_{\text {amp }} * K *\left(\frac{d}{2}\right)^{2}\right)
$$

non-cluster nodes send the data to their major head [9]. The clustering approach is adopted because many nodes send same data in the network due to which there is a lot of redundancy. Because of the clustering of the similar nodes in one $\mathrm{CH}$, the data is composited and is transferred to head that processes and transferred the data to another node. This protocol lessens the communication energy being degenerated by $\mathrm{CH}$ and member to eight times. 

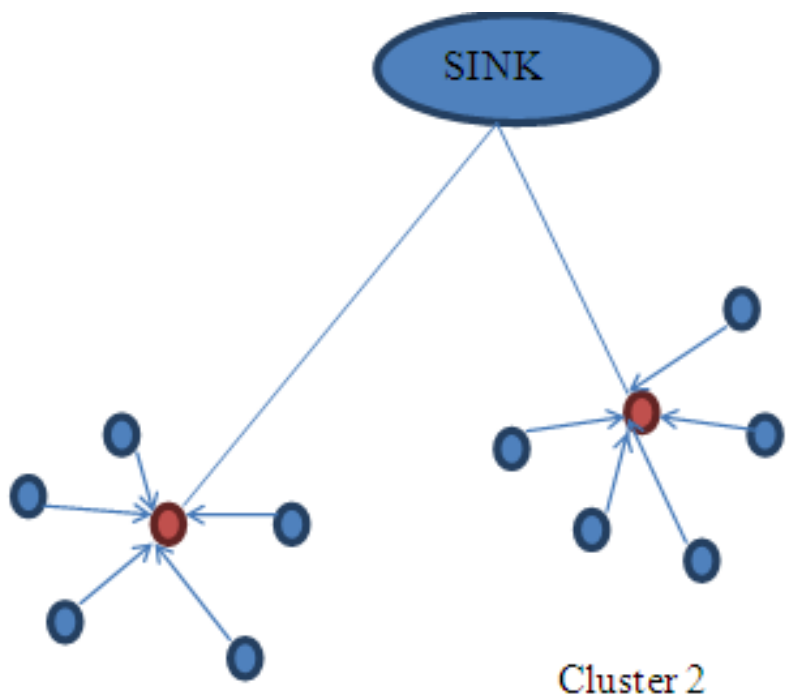

\section{O Cluster head \\ O Member node}

\section{Cluster 2}

\section{Cluster 1}

Figure 3. Leach (Low energy Adaptive Clustering Hierarchy)protocol

LEACH protocol has arbitrary rotation with enhanced energy $\mathrm{CH}$ position so that it surrounds between the sensors to evade the battery drainage of some sensor in the network.

By applying this process, the energy load linked with a cluster-head is consistently distributed among the nodes. As the cluster-head node has knowledge of all the cluster members, a TDMA schedule is created that tells the time at which every node needs to transmit the data. Furthermore, by utilizing TDMA schedule for transmitting the data by circumventing the intra-cluster collisions [10].

The process of LEACH is separated into rounds. Each round starts with set-up phase in which cluster organization take place. After that, steady-state phase occurs where numerous frames of information are transmitted from the member nodes to the cluster-head and at last to the base station [11].

Table 1. Phases of LEACH

\begin{tabular}{|c|c|}
\hline Phases of LEACH & Description \\
\hline \multirow[t]{5}{*}{ Set-up phase } & Clusters are organized and cluster head is selected. \\
\hline & $\begin{array}{l}\text { Any random number is selected by the each node between } 0 \text { and } 1 \text { and comparison is done } \\
\text { with the threshold computed by the given equation } 3 \text {, if the number selected by node is less } \\
\text { as compare to threshold, the nodes is chosen as the cluster head }\end{array}$ \\
\hline & $\begin{array}{l}\mathbf{T}(\mathbf{n})=\frac{\mathbf{P}}{\mathbf{1 - P} *\left(\mathbf{r} \mathbf{m o d} \frac{\mathbf{1}}{\mathbf{p}}\right)} \text { if } \mathbf{n} \in \mathbf{G}, \mathbf{0} \\
\text { In equation } 4 \text { the terms referred are described below: } \\
\mathbf{r}=\text { current round }\end{array}$ \\
\hline & $\mathbf{G}=$ Set of those nodes which have not been cluster head in last $\frac{\mathbf{1}}{\mathbf{p}}$ rounds \\
\hline & $\begin{array}{l}\qquad \mathbf{P}=\text { cluster head percentage } \\
\text { In every round a message is forwarded by selected cluster head to the nodes to inform about } \\
\text { their status. } \\
\text { TDMA is generated and schedules are forwarded. }\end{array}$ \\
\hline Steady phase & $\begin{array}{l}\text { Nodes transmit the data and the cluster head do the data aggregating, fusion and } \\
\text { compressing process and in addition forward the data to the base station. }\end{array}$ \\
\hline
\end{tabular}

After the completion of one round, next round is started advantages there are some limitations of LEACH protocol which are described in table 2: which selects all over again with new priorities. With the

Table 2. Limitation of Leach Protocol

\begin{tabular}{|c|c|}
\hline S.No & Limitations of $\mathbf{L E A C H}$ \\
\hline 1 & $\begin{array}{c}\text { As the energy consumption is the main problem in the network, LEACH does not take the residual } \\
\text { energy of nodes for choosing the cluster heads. }\end{array}$ \\
\hline 2 & $\begin{array}{r}\text { When the node of low energy (who can be CH due to the network probabilistic nature) dies , whole } \\
\text { cluster becomes dysfunctional. }\end{array}$ \\
\hline 3 & Some CH's are not distributed well in the network \\
\hline 4 & LEACH is not appropriate for wireless sensors in large areas \\
\hline
\end{tabular}




\section{HEED (Hybrid Energy Efficient Distributed Clustering)}

HEED is considered as the effective clustering dependent technique in WSN for routing. It is energy efficient as well as distributed. [12]:

It takes two parameters in account which are as follows a) Sensor residual energy: Primary parameter

b) Intra communication (node degree and bode proximity): Secondary parameter

There are some objectives which are focused to accomplish to make the network more reliable are discussed in table 2.

Table 3. Objectives of HEED

\begin{tabular}{|c|c|}
\hline S.NO & Objectives of HEED \\
\hline 1 & Extending network lifetime by allocating energy consumption \\
\hline 2 & Dismissing the clustering process inside a constant number of iterations \\
\hline 3 & Reducing control overhead \\
\hline 4 & Creating cluster-heads which are well-distributed \\
\hline
\end{tabular}

There are three phases in the HEED through which the whole process of energy efficient clustering takes place. The table explains the phases with the description in table 4 .

Table 4. Phases of HEED

\begin{tabular}{|c|c|c|}
\hline S.NO & Phases of HEED & Description \\
\hline 1 & $\begin{array}{c}\text { Initialization } \\
\text { phase }\end{array}$ & Sensors put their possibilities to turn into CHs. \\
\hline 2 & $\begin{array}{c}\text { Main processing } \\
\text { phase }\end{array}$ & Sensors go through various steps to get chosen for the CHs \\
\hline 3 & Finalization phase & $\begin{array}{c}\text { Every sensor join least communication-cost Cluster head or proclaim itself as a } \\
\text { Cluster head }\end{array}$ \\
\hline
\end{tabular}

The HEED clustering process is mainly for invoking every node for electing the cluster head or become a member. The dependability of the cluster head is to create inter-cluster co-ordination with intra-cluster communication.

\section{1) PEGASIS}

It is the improvement in the routing protocol of LEACH in wireless senor network and stands for power efficient gathering in sensor information. Each sensor joins the least communication-cost $\mathrm{CH}$ or announces itself as a $\mathrm{CH}$ [13]. In PEGASIS, one node is considered as $\mathrm{CH}$ node that transfers the collective data to the base station round.
It is optimal chain-based protocol which is enhancement over LEACH protocol. In this, each node communicates by nearest neighbor and later it sends the data to the base station. It has better computational power than LEACH. The data is fused with the help of different sensor measurement to create a single packet. The main goal is to create a chain in the nodes which connect all the nearest nodes to each other so that the sending and receiving can be from the neighbor node. The data usually moved from one node towards another and ultimately, last node transfers it to the base station. There are different steps in the PEGASIS protocol which is described in table 4.

Table 5. Stages in PEGASIS protocol

\begin{tabular}{|c|c|}
\hline Steps & Description \\
\hline $\begin{array}{c}\text { Chain } \\
\text { construction }\end{array}$ & $\begin{array}{r}\text { The chain is constructed from the farthest node to the base station to send and receive data } \\
\text { through the nodes as data is transmitted to the nearest neighbour. }\end{array}$ \\
\cline { 2 - 2 } & $\begin{array}{r}\text { This whole process is created by using the greedy approach. } \\
\text { Gathering data }\end{array}$ \\
\cline { 2 - 2 } & $\begin{array}{r}\text { Leader of every node is randomly selected. If number of nodes = N, I = round so } \\
\text { i mode is chosen as the main node. }\end{array}$ \\
\cline { 2 - 2 } & $\begin{array}{r}\text { With the termination of various nodes, the chain get reconstructed to ignore the dead node. } \\
\hline\end{array}$ \\
\hline
\end{tabular}

D. Performance Metrics of WSN

The wireless sensor systems are evaluated on the basis of various parameters. These parameters show the performance and quality of system at different environmental conditions [14].

Table 6. Parameters description

\begin{tabular}{|c|c|}
\hline Parameters & Description \\
\hline Network lifetime & $\begin{array}{l}\text { Each node in the wireless sensor network should be planned to manage the supply of } \\
\text { energy to prolong network's lifetime. }\end{array}$ \\
\hline Coverage & The coverage of the network nodes is helpful when the nodes are dispersed all over the \\
\hline
\end{tabular}




\begin{tabular}{|c|c|}
\hline Scalability & area to be monitored. \\
\hline Response time & $\begin{array}{c}\text { Response time must be fast for alarm oriented application in the WSN application like } \\
\text { Fire Detection }\end{array}$ \\
\hline Temporal accuracy & $\begin{array}{c}\text { The co-relation of samples should be done on time and exact measurement should be } \\
\text { send to user }\end{array}$ \\
\hline Cost & $\begin{array}{c}\text { For a prolonged network the sensor node should be accurately done and on accurate } \\
\text { distance which should be measured initially. }\end{array}$ \\
\hline
\end{tabular}

\section{OPTIMIZATION TECHNIQUES}

These techniques are used for enhancing the energy efficiency of the network clusters, prolonging the network lifetime and resolve issues related to the data aggregation, clustering and node localization.

A. Genetic algorithm

GA enables development of the population using operators such as crossover, mutation, and selection. It also assists in generating energy effective clusters and later chooses their members [15]. The output of the GA identifies the best cluster head for the network. By using the minimal distance technique, the base station gives member nodes to each of the cluster heads. The entire information is transmitted to the sensor node with the help of base station.

Nodes in the wireless network are defined by the bits of chromosome. The fitness of these chromosomes is defined by many parameters such as energy consumption and node density. The fitness parameter is created to lessen the energy consumption and prolong the network lifetime. Few fitness parameters are described below in table 7:

Table 7. Fitness Parameters

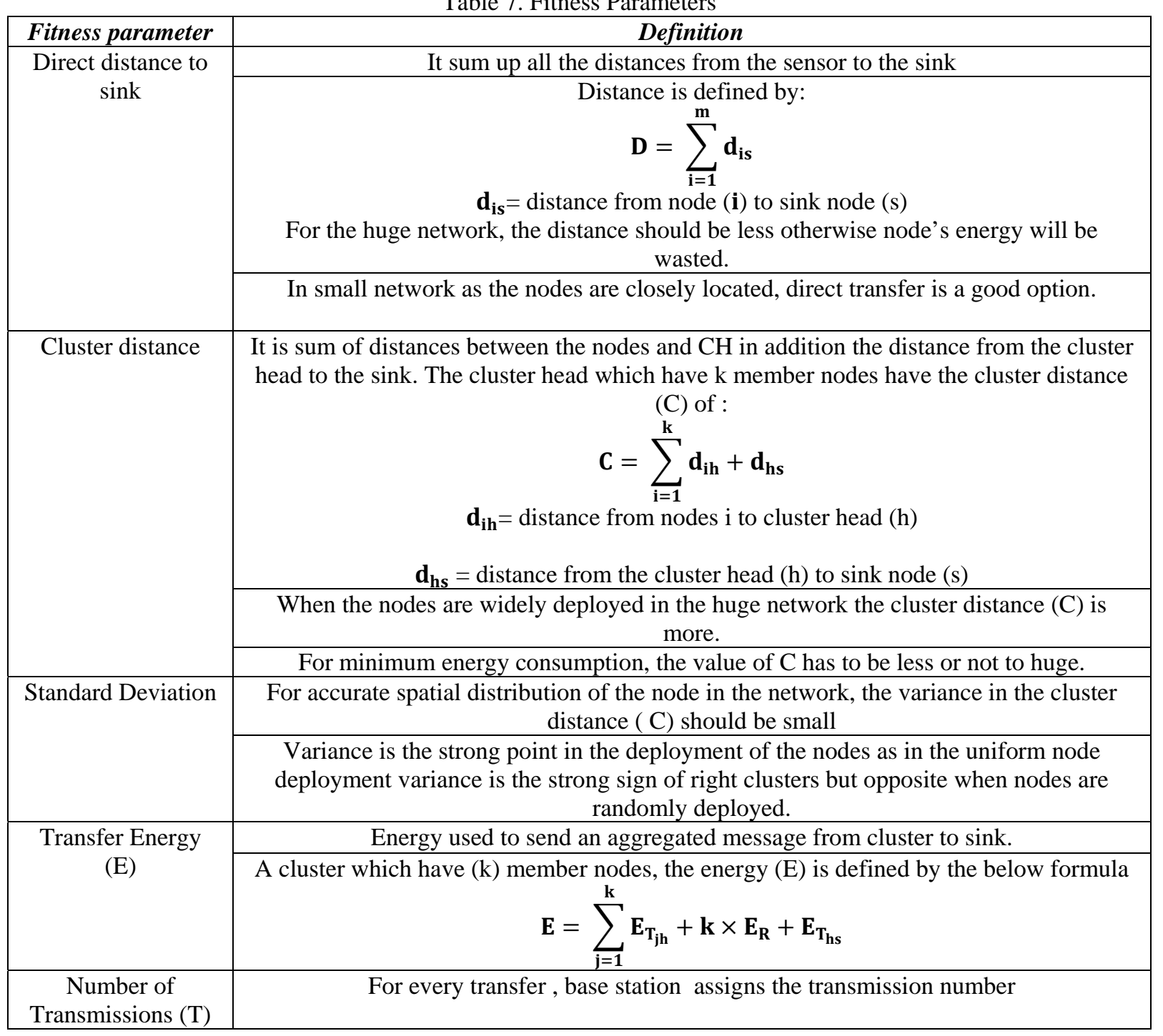

\section{B. Ant bee colony optimization}

The main aim of this algorithm in the wireless sensor networks is to prolong the network life time by maximizing transferred amount of data packets through clustering. The cluster head formation is done by the ABC algorithm. In the [16], LEACH and the ABC algorithm works together to perform the data aggregation technique for cluster head. 


\section{Particle swarm optimization}

This algorithm behaves like flock of birds. It contains a swarm of $\mathrm{k}$ candidates that discover an-dimensional hyperspace in hunt of global solution. Here $\mathrm{n}$ defines the amount of correct parameters which are to be determined. Every particle in hyperspace is evaluated through an objective function $\mathrm{f}(\mathrm{x} 1, \mathrm{x} 2, \mathrm{x} 3 \ldots \ldots \mathrm{xn})$. The fitness of particle near to global solution is higher than particle which is far away. Many of the methods suffer from lack of convergence to final solution so at this point the particle swarm optimization technique is used for creating the quality solution by utilizing minimum resources. It is an extremely accepted technique for resolving the issues of optimization in WSN because of its high QoS (Quality of Service), fast convergence with it simplicity [17]. Its main function is to resolve the issue of the wireless sensor network like optimal deployment, clustering, data aggregation and node localization. It also thrives to change the fitness function according to some circumstances. There are some advantages of the particle swarm optimization which makes it more efficient for large network which is described in table 7.

Table 8. Advantages of PSO

\begin{tabular}{|c|c|}
\hline S.No & Advantages of the PSO \\
\hline 1 & Can be easily implemented on hardware or software \\
\hline 2 & Availability of different guidelines for selecting the parameters \\
\hline 3 & As it can easily escape from the local optima, it results in high quality solutions. \\
\hline 4 & Availability of alternatives for real, binary domains and integers. \\
\hline 5 & Fast convergence \\
\hline
\end{tabular}

\section{RELATED WORK}

The comparative analyses of the previous clustering techniques are done to show the relative results of the combination of different techniques with different wireless sensor networks.

Table 9. Comparison of existing approaches

\begin{tabular}{|c|c|c|c|}
\hline Author & Algorithm used & Advantage & Result \\
\hline \multirow[t]{3}{*}{ Hoda Taheri [4] } & \multirow{3}{*}{$\begin{array}{c}\text { Energy aware distributed } \\
\text { dynamic clustering protocol } \\
\text { was proposed }\end{array}$} & \multirow{2}{*}{$\begin{array}{l}\text { Remaining energy of nodes } \\
\text { was used for selecting the } \\
\text { next cluster head }\end{array}$} & $\begin{array}{c}\text { Network life time was } \\
\text { prolonged }\end{array}$ \\
\hline & & & \multirow[t]{2}{*}{ Saved energy } \\
\hline & & $\begin{array}{c}\text { Fuzzy was implied to } \\
\text { evaluate the fitness cost of } \\
\text { node }\end{array}$ & \\
\hline \multirow[t]{3}{*}{$\begin{array}{l}\text { Mehdi Tarhani } \\
\text { [5] }\end{array}$} & \multirow[t]{3}{*}{$\begin{array}{l}\text { Distributed algorithm named } \\
\text { scalable energy efficient } \\
\text { clustering hierarchy (SEECH }\end{array}$} & \multirow{2}{*}{$\begin{array}{l}\text { Chosen CHs and relays } \\
\text { separately and based on } \\
\text { nodes eligibilities due to } \\
\text { more energy efficiency was } \\
\text { achieved. }\end{array}$} & $\begin{array}{l}\text { Better than LEACH and } \\
\text { TCAC in terms of } \\
\text { cluster head distribution } \\
\end{array}$ \\
\hline & & & \multirow[t]{2}{*}{$\begin{array}{c}\text { Fine for huge scale } \\
\text { networks }\end{array}$} \\
\hline & & $\begin{array}{c}\text { Modified CHs energy } \\
\text { burden process as it was } \\
\text { distributed clearly. } \\
\end{array}$ & \\
\hline \multirow[t]{3}{*}{$\begin{array}{c}\text { Ruonan Zhang } \\
\text { [6] }\end{array}$} & \multirow[t]{3}{*}{$\begin{array}{c}\text { Hybrid approach was } \\
\text { proposed, known as Node } \\
\text { Density based Clustering and } \\
\text { Mobile Collection (NDCMC) }\end{array}$} & \multirow[t]{2}{*}{$\begin{array}{l}\text { Combined hierarchical } \\
\text { routing and Mobile element } \\
\text { data gathering in WSNs. }\end{array}$} & $\begin{array}{l}\text { Enhanced efficiency of } \\
\text { intra-cluster routing with } \\
\text { Mobile element data } \\
\text { compilation. } \\
\text { Suitable trade-off amid } \\
\text { the network energy } \\
\text { saving and data }\end{array}$ \\
\hline & & & \multirow[t]{2}{*}{ Collection latency. } \\
\hline & & $\begin{array}{l}\text { Nodes which were bounded } \\
\text { by more installed nodes are } \\
\text { more expected to be Cluster } \\
\text { heads }\end{array}$ & \\
\hline \multirow[t]{3}{*}{ Dali Wei [7] } & \multirow{3}{*}{$\begin{array}{c}\text { Distributed clustering } \\
\text { algorithm, Energy-efficient } \\
\text { Clustering (EC }\end{array}$} & \multirow{2}{*}{$\begin{array}{c}\text { Decided suitable cluster } \\
\text { sizes depending on hop } \\
\text { distance to data sink } \\
\end{array}$} & $\begin{array}{c}\text { Extended network } \\
\text { lifetime }\end{array}$ \\
\hline & & & \multirow{2}{*}{$\begin{array}{l}\text { Achieved energy } \\
\text { equalization more } \\
\text { efficiently than two }\end{array}$} \\
\hline & & $\begin{array}{l}\text { Attained predictable } \\
\text { equalization of the node }\end{array}$ & \\
\hline
\end{tabular}




\begin{tabular}{|c|c|c|c|}
\hline & & lifetime & $\begin{array}{c}\text { clustering procedures, } \\
\text { HEFD and UCR }\end{array}$ \\
\hline & & $\begin{array}{l}\text { Reduced levels of energy } \\
\text { consumption }\end{array}$ & \\
\hline $\begin{array}{c}\text { Jin-Shyan Lee } \\
{[8]}\end{array}$ & $\begin{array}{l}\text { hybrid hierarchical clustering } \\
\text { approach (HHCA) }\end{array}$ & $\begin{array}{l}\text { Extensional work on } \\
\text { former two-layer based } \\
\text { LEACH clustering } \\
\text { approach. }\end{array}$ & $\begin{array}{c}\text { Energy conservation } \\
\text { was achieved. }\end{array}$ \\
\hline & & $\begin{array}{c}\text { Grid heads were } \\
\text { determined in centralized } \\
\text { manner whereas cluster } \\
\text { heads were found in } \\
\text { distributed manner } \\
\text { Number of nodes which } \\
\text { connected with base station } \\
\text { were reduced }\end{array}$ & \\
\hline $\begin{array}{c}\text { Kun-chan Lan } \\
\text { [9] }\end{array}$ & $\begin{array}{c}\text { Compressibility-Based } \\
\text { Clustering Algorithm (CBCA) } \\
\text { for Hierarchical Compressive } \\
\text { Data Gathering }\end{array}$ & $\begin{array}{l}\text { Enabled less data } \\
\text { transmission as compare to } \\
\text { random Clustering method } \\
\text { formerly used for HCDG }\end{array}$ & $\begin{array}{c}\text { Achieved PRD } \\
\text { (Percentage Root-mean } \\
\text { squared Distortion) of } \\
\text { less than 5\% }\end{array}$ \\
\hline $\begin{array}{l}\text { Mihaela I. } \\
\text { Chidean [10] }\end{array}$ & $\begin{array}{l}\text { In-network processing } \\
\text { methods and clustering }\end{array}$ & $\begin{array}{l}\text { Controlled number of } \\
\text { transmissions with high }\end{array}$ & $\begin{array}{c}\text { Energy efficiency was } \\
\text { achieved }\end{array}$ \\
\hline & algorithms were jointly used & $\begin{array}{l}\text { data qualityby usage of } \\
\text { aggregation function and an } \\
\text { energy efficient network } \\
\text { partition. }\end{array}$ & $\begin{array}{c}\text { Good data quality was } \\
\text { achieved }\end{array}$ \\
\hline & & $\begin{array}{c}\text { Increased energy } \\
\text { efficiency, though no data } \\
\text { quality was sacrificed }\end{array}$ & \\
\hline $\begin{array}{c}\text { Salim EL } \\
\text { KHEDIRI [12] }\end{array}$ & $\begin{array}{l}\text { Low Energy Adaptive } \\
\text { Clustering Hierarchy (O- }\end{array}$ & $\begin{array}{l}\text { Minimized traffic in the } \\
\text { network. }\end{array}$ & $\begin{array}{l}\text { Achieved longer } \\
\text { stability of static }\end{array}$ \\
\hline & LEACH) & Lessen energy consumption & networks \\
\hline & & $\begin{array}{l}\text { Accurate cluster is being } \\
\text { selected on the basis of } \\
\text { residual energy for the } \\
\text { nodes }\end{array}$ & \\
\hline Sadia Din [13] & hybrid algorithm & $\begin{array}{l}\text { Blind broadcast messages } \\
\text { were efficiently reduced }\end{array}$ & $\begin{array}{c}\text { Less energy } \\
\text { consumption }\end{array}$ \\
\hline & & and also decreased the & Reduced packet loss \\
\hline & & $\begin{array}{l}\text { signal overhead which was } \\
\text { due to cluster formation. }\end{array}$ & Good cluster formation \\
\hline & & $\begin{array}{l}\text { Efficiently minimized the } \\
\text { direction-finding paths } \\
\text { toward the base station }\end{array}$ & \\
\hline
\end{tabular}

\section{EXISTING WORK}

Depending on the different clustering algorithms and optimization techniques, different authors have proposed different results based on the parameters such as energy consumption, network lifetime, nodes distance and reduction in packet loss. The comparative analysis of network lifetime has been taken place. The description is given below:
When there are long transmission distances between the cluster head and the base station, the energy is consumed more. So in the [6], the comparison between the leach protocol and node density based clustering and mobile collection is done on basis of long network lifetime. The result shows that the $50 \%$ of the network lifetime is increased with the usage of NDCMC is depicted in table below:

Table 10. Comparison between the NDCMC and LEACH [6]

\begin{tabular}{|c|c|}
\hline Algorithms & Longest Network life time \\
\hline LEACH & $7 * 102$ \\
\hline NDCMC & $2.2 * 108$ \\
\hline
\end{tabular}




\section{CONCLUSION}

Energy conservation is a significant issue in wireless sensor networks. To have the effective energy, variety of clustering algorithms have been presented. This paper presented different clustering approaches which makes the cluster formation and choosing of $\mathrm{CH}$ in a better manner. These clustering approaches are used in multi-hop scenarios in WSN networks. The extended o-leach protocol is considered as way better than the former leach protocol. In the studies, many hybrid approaches were created which reduced the packet loss and energy consumption. The comparison study of the existing approaches has been done which shows the hybrid approach with optimization algorithm is better than the sole algorithm.

\section{REFERENCES}

[1] Abbasi, A. A., \&Younis, M, "A survey on clustering algorithms for wireless sensor networks," Computer communications, vol. 30, no. 14, pp. 2826-2841,2007.

[2] Younis, O., Krunz, M., \&Ramasubramanian, S, Node clustering in wireless sensor networks: Recent developments and deployment challenges, IEEE network, vol. 20, no. 3,pp. 20-25,2006.

[3] Xie, G., \& Pan, F., "Cluster-based routing for the mobile sink in wireless sensor networks with obstacles, IEEE Access, vol. 4, pp.2019-2028, 2016.

[4] Taheri, H., Neamatollahi, P., Younis, O. M., Naghibzadeh, S., \&Yaghmaee, $\quad M$. H., "An energy-aware distributed clustering protocol in wireless sensor networks using fuzzy logic," Ad Hoc Networks, vol. 10. no.7, pp.1469-1481,2012.

[5] Tarhani, M., Kavian, Y. S., \&Siavoshi, S., "SEECH: Scalable energy efficient clustering hierarchy protocol in wireless sensor networks," IEEE Sensors Journal, vol. 14, no.11, pp.3944-3954, 2014.

[6] Zhang, R., Pan, J., Xie, D., \& Wang, F., "Ndcmc: A hybrid data collection approach for large-scale wsns using mobile element and hierarchical clustering,” IEEE Internet of Things Journal, vol. 3, no. 4, pp.533-543, 2016.

[7] Wei, D., Jin, Y., Vural, S., Moessner, K., \&Tafazolli, R., “An energy-efficient clustering solution for wireless sensor networks," IEEE transactions on wireless communications, vol. 10, no.11, pp. 3973-3983,2011.

[8] Lee, J. S., \& Kao, T. Y, “An improved three-layer low-energy adaptive clustering hierarchy for wireless sensor networks,” IEEE Internet of Things Journal, vol.3, no. 6, pp. 951-958,2016.

[9] Lan, K. C., \& Wei, M. Z, "A Compressibility-Based Clustering Algorithm for Hierarchical Compressive Data Gathering,” IEEE Sensors Journal, vol. 17, no. 8, pp. 25502562, 2017.

[10] Chidean, M. I., Morgado, E., Sanromán-Junquera, M., Ramiro-Bargueno, J., Ramos, J., \&Caamano, A. J, “Energy efficiency and quality of data reconstruction through datacoupled clustering for self-organized large-scale WSNs,” IEEE Sensors Journal, vol. 16, no. 12, pp. 5010$5020,2016$.

[11] Singh, S. K., Kumar, P., \& Singh, J. P, "A Survey on Successors of LEACH Protocol,” IEEE Access, vol. 5, pp. 4298-4328,2017.

[12] Khediri, S. E., Nasri, N., Wei, A., \&Kachouri, A, “A new approach for clustering in wireless sensors networks based on LEACH,” Procedia Computer Science, vol. 32, pp.1180-1185, 2014.

[13] Din, S., Ahmad, A., Paul, A., Rathore, M. M. U., \& Jeon, G, "A Cluster-Based Data Fusion Technique to Analyze Big Data in Wireless Multi-Sensor System,” IEEE Access, vol. 5, pp. 5069-5083,2017.

[14] Takaishi, D., Nishiyama, H., Kato, N., \& Miura, R, “Toward energy efficient big data gathering in densely distributed sensor networks, "IEEE Transactions on Emerging Topics in Computing, vol. 2, no. 3, pp. 388-397,2014.

[15] Hussain, S., Matin, A. W., \& Islam, O., "Genetic algorithm for energy efficient clusters in wireless sensor networks, Information Technology, IEEE Fourth International Conference, pp. 147-154, 2007.

[16] Karaboga, D., Okdem, S., \&Ozturk, C., "Cluster based wireless sensor network routing using artificial bee colony algorithm,” Wireless Networks, vol. 18, no. 7, pp. 847-860,2012.

[17] Kulkarni, R. V., \&Venayagamoorthy, G. K, "Particle swarm optimization in wireless-sensor networks: A brief survey," IEEE Transactions on Systems, Man, and Cybernetics, Part C (Applications and Reviews), vol. 41, no. 2, pp. 262-267, 2011. 